AperTO - Archivio Istituzionale Open Access dell'Università di Torino

\title{
Subtle structural changes in the Asp251Gly/GIn307His P450 BM3 mutant responsible for new activity toward diclofenac, tolbutamide and ibuprofen
}

\section{This is the author's manuscript}

Original Citation:

Availability:

This version is available http://hdl.handle.net/2318/1544804

since 2017-06-20T11:31:46Z

Published version:

DOI:10.1016/j.abb.2015.12.005

Terms of use:

Open Access

Anyone can freely access the full text of works made available as "Open Access". Works made available under a Creative Commons license can be used according to the terms and conditions of said license. Use of all other works requires consent of the right holder (author or publisher) if not exempted from copyright protection by the applicable law. 


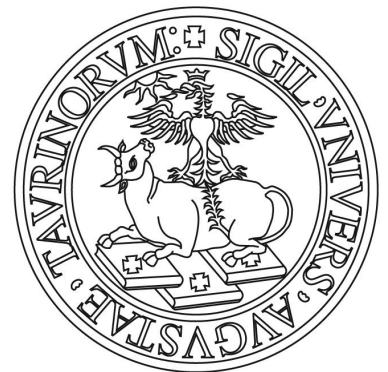 \\ UNIVERSITÀ DEGLI STUDI DI TORINO}

This is the accepted version of the following article:

[Di Nardo G, Dell'Angelo V, Catucci G, Sadeghi SJ, Gilardi G. Subtle structural changes in the Asp251Gly/Gln307His P450 BM3 mutant responsible for new activity toward diclofenac, tolbutamide and ibuprofen. Arch. Biochem. Biophys. 2015 pii: S0003-9861(15)301168.],

which has been published in final form at [http://www.sciencedirect.com/science/article/pii/S0003986115301168] 
Subtle structural changes in the Asp251Gly/GIn307His P450 BM3 mutant responsible for new activity toward diclofenac, tolbutamide and ibuprofen.

Giovanna Di Nardo ${ }^{a, b}$, Valentina Dell'Angelo ${ }^{a}$, Gianluca Catucci ${ }^{a}$, Sheila J. Sadeghi ${ }^{a}$, Gianfranco Gilardi ${ }^{\mathrm{a}, \mathrm{b}, *}$

a Department of Life Sciences and Systems Biology, University of Torino, Via Accademia Albertina 13, Torino, Italy

${ }^{\mathrm{b}}$ CrisDi, Interdepartmental Center for Crystallography, University of Torino, Via Pietro Giuria 7, Torino, Italy 


\section{Abstract}

This paper reports the structure of the double mutant Asp251Gly/GIn307His (here called A2), generated by random mutagenesis, is able to produce 4'hydroxydiclofenac, 2-hydroxyibuprofen and 4-hydroxytolbutamide from diclofenac, ibuprofen and tolbutamide, respectively. Here, we report the crystal structure of the heme domain of the mutant in the substrate-free form and in complex with the substrate N-palmitoylglycine, together with its impact on thermal stability, reduction potential and electron transfer.

The substrate-free structure adopts a conformation more similar to the closed one found in the substrate-bound wild type enzyme, but with a higher degree of disorder in the region of the G-helix and F-G loop, part of the substrate access channel. This is due to the mutation Asp251Gly that breaks the salt bridge between Aps251 on Ihelix and Lys224 on G-helix, allowing the G-helix to move away from I-helix and conferring a higher degree of flexibility to this element. This subtle structural change is accompanied by long-range structural rearrangements of the active site with the rotation of Phe87 and a reorganization of catalytically important water molecules.

Differential scanning calorimetry shows a population destabilized by $2.2^{\circ} \mathrm{C}$ compared to the wild type protein, probably reflecting the increased flexibility of part of the protein compared to WT. Moreover, a shift of the heme reduction potential by $50 \mathrm{mV}$ toward positive values, a 2-folds higher first electron transfer rate in the absence of oxygen and a 4-folds higher NADPH consumption rate in the presence of oxygen as the only electron acceptors, when compared to wild type protein.

The data demonstrate that a single mutation far away from the active site is able to trigger an increase in protein flexibility in a key region of the substrate access channel, shifting the conformational equilibrium toward the closed form of the protein that is ready to accept electrons and enter the P450 catalytic cycle as soon as a substrate is accepted.

\section{Keywords}

Cytochrome P450, biocatalysis, protein engineering, conformational equilibrium

Introduction 
Cytochrome P450 enzymes are heme-thiolate monoxygenases interesting for biocatalytic purposes for their ability of $\mathrm{C}-\mathrm{H}$ bond functionalization [1]. They have a large potential in fields such as drug discovery, fine chemicals synthesis, bioremediation, and biotechnology. In particular, those from human liver are responsible for Phase I metabolism of drugs, that are converted in one or more metabolites. The toxicity and biological activity of such metabolites have to be fully characterised during the development of new drugs as they can cause adverse reactions in the human body [2]. It is necessary therefore to synthesize preparative amounts of these compounds to assess their toxicity, a process that is difficult to achieve by classical synthetic methods. The direct use of human cytochrome P450 is limited by the need of a redox partner and the poor stability and activity. However, bacterial counterparts such as cytochrome P450 BM3 (CYP102A1) from Bacillus megaterium, can be directly used [3] or engineered to metabolise drugs and to produce the same metabolites as the human enzymes [4-14]. This protein is a selfsufficient fatty acids monoxygenase containing a NADPH-dependent reductase (BMR) and a P450 catalytic domain (BMP) fused in a single polypeptidic chain $[15,16]$. The high catalytic efficiency makes it an excellent template for protein engineering aimed at improving substrate versatility and catalytic activity towards drugs for the generation of metabolites [14,17-20].

Random mutagenesis is a potentially successful approach to introduce new functions in enzymes for biocatalytic purposes. However, only the structural characterization of the improved variants can elucidate the effect of the randomly introduced mutations on protein structure and function, offering the basis for understanding how and why an enzyme has evolved to recognize and turn over new molecules. Here, we report the crystal structure of the heme domain of the double mutant D251G/Q307H of cytochrome P450 BM3, named A2, previously generated and characterized from a catalytic point of view for its ability to generate metabolites of diclofenac, ibuprofen and tolbutamide [9]. The information from the crystal structure of the mutant also in complex with the substrate $\mathrm{N}$-palmytoilglycine together with the comparison with the available structures of the wild type enzyme [21,22] were then used for a more detailed and comparative functional characterization, giving the rational basis to understand why the A2 mutant has evolved toward the recognition and the turnover of new substrates due to two mutations far from its active site. 


\section{Experimental section}

\section{Materials}

All chemicals used for protein expression, purification, characterization and crystallization were purchased from Sigma-Aldrich and were analytical grade. Restriction enzymes were purchased from New England Biolabs.

Generation of the heme domain (BMP) of the mutant $A 2$-The fragment of the gene encoding for the heme domain of cytochrome P450 BM3 A2 was extracted by digestion with specific restriction enzymes (BamHI and $\mathrm{Mscl})$ and ligated into a pT7 expression vector. The correct insertion of the fragment containing the mutations was verified by DNA sequencing.

Protein expression, purification and quantification - Expression was carried out in E.coli BL21 (DE3) cells in Luria-Bertani (LB) medium containing $100 \mu \mathrm{g} \mathrm{mL}^{-1}$ of ampicillin. Cells were grown until the $\mathrm{OD}_{600}$ was 0.7 in $500 \mathrm{~mL}$ flask containing 100 $\mathrm{mL}$ of LB medium. Then, the culture was diluted again 1:100 transferring $10 \mathrm{~mL}$ of the cells grown up to $\mathrm{OD}_{600}$ value of 0.7 into $2 \mathrm{~L}$ flasks containing $1 \mathrm{~L}$ of medium. Once reached an $\mathrm{OD}_{600}$ value of 0.7 , protein expression was induced by adding 1 mM IPTG. The expression was carried out for $19 \mathrm{~h}$ at $28{ }^{\circ} \mathrm{C}, 180 \mathrm{rpm}$ shaking. Following cell growth, bacterial cells were recovered by centrifugation at $4{ }^{\circ} \mathrm{C}$ and resuspended in Buffer $\mathrm{A}$ (30 mM KPi pH 7.4, 2 mM DTT, $0.1 \mathrm{mM}$ EDTA) containing $0.1 \mathrm{mM}$ phenyl methyl sulfonyl fluoride (PMSF) and $0.2 \mathrm{mg} \mathrm{mL}^{-1}$ lysozyme. Cells were lysed by sonication and the soluble fraction was separated form cell debris by centrifugation at $40000 \mathrm{rpm}$ for 25 at $4{ }^{\circ} \mathrm{C}$. Purification was carried out with some modifications as described before [23]. Briefly, a double step anion-exchange chromatography using a diethylaminoethyl (DEAE-Sepharose Fast-Flow, GE healthcare) and a Q-Sepharose columns (Q-Sepharose Fast Flow, GE Healthcare). The fractions containing A2 mutant were pooled and loaded into a $150 \mathrm{~mL}$ DEAE column and eluted using a $50-250 \mathrm{mM} \mathrm{NaCl}$ gradient $(500 \mathrm{~mL})$. The protein was then exchanged into Buffer A using an Amicon centrifugal filter (Millipore, $30 \mathrm{KDa}$ cut-off) in order to remove salt excess and loaded into a Q-Sepharose chromatography column $(70 \mathrm{~mL})$. The protein was eluted as reported previously for the DEAE and the buffer containing $\mathrm{NaCl}$ was exchanged with storage buffer $100 \mathrm{mM} \mathrm{KPi} \mathrm{pH} \mathrm{8.0.} \mathrm{The}$ fractions containing $\mathrm{A} 2$ mutant were analysed for purity by SDS-PAGE gel and 
pooled according to the purity ratio $\left(\mathrm{A}_{418} / \mathrm{A}_{280}=1.3\right)$. A CO-binding assay was performed on the purified P450 BM3 WT and A2 proteins in order to estimate their concentration in a UV-Vis spectrophotometer (Agilent Technologies) using a $1 \mathrm{~cm}$ pathlength quartz cuvette, according to the method described by Omura and Sato [24]. The protein concentration used to perform the assay was $1 \mu \mathrm{M}$. After the formation of the $\mathrm{Fe}(\mathrm{II}) \mathrm{CO}$ complex at $450 \mathrm{~nm}$ by bubbling $\mathrm{CO}$ to the sodium dithionite-reduced protein, the extinction coefficient of $91000 \mathrm{M}^{-1} \mathrm{~cm}^{-1}$ was used to estimate protein concentration using as absorbance value the $\Delta \mathrm{Abs}_{450-490}$.

Crystallization and determination of protein structures - Crystallization was achieved by vapor diffusion method in 24-well sitting drop plates at $4{ }^{\circ} \mathrm{C}$. Using a protein:reservoir ratio of 1:1, P450 BMP A2 (20 mg mL $\left.{ }^{-1}\right)$ was mixed with crystallization cocktails containing 14\% PEG 3350, $100 \mathrm{mM}$ cacodylic acid in a pH range from 5.5 to 6.8 and $\mathrm{MgCl}_{2}$ from 100 to $160 \mathrm{mM}$. For the N-palmitoylglycine (NPG) bound form, the protein was saturated with the ligand and co-crystallized. NPG was titrated into BMP sample until full shift to $398 \mathrm{~nm}$ was observed. The protein was immediately concentrated by ultrafiltration in the presence of saturating ligand and used for crystallization purposes. Red crystals were obtained after 3-4 weeks and were flash-frozen in liquid nitrogen using 10\% w/v PEG200 as a cryoprotectant. X-ray diffraction data were collected on the ID29 at the European Synchrotron Research Facility (Grenoble, France) [25] and on the BL13-XALOC beamline at ALBA synchrotron (Cerdanyola del Vallès, Spain) [26]. Data were processed using XDS [27] and scaled using AIMLESS [28]. The structure was solved by molecular replacement using Molrep [29] from the CCP4 suite [30] and the coordinates of the heme domain of P450 BM3 structure (PDB 1JPZ) [22]. The models were adjusted using Coot [31] and refined using Refmac5 [32] and PHENIX [33]. Coordinates and structure factors have been deposited in the Protein Data Bamk (PDB) with accession code 5DYP and 5DYZ.

Fatty acids binding and NADPH consumption studies - Dissociation constants $\left(\mathrm{K}_{\mathrm{D}}\right)$ for binding of the substrate N-palmitoylglycine (NPG) were determined by UV-Vis spectrophotometer (Agilent Technologies) in a $1 \mathrm{~cm}$ path length quartz cuvette by following the typical low-to-high-spin transitions. The reaction mixture contains $1 \mu \mathrm{M}$ of enzyme and substrate in a concentration range from 0.05 to $15 \mu \mathrm{M}$. Each spectrum was recorded after 3 minutes of equilibration upon each substrate addition 
at $25^{\circ} \mathrm{C}$ in a $100 \mathrm{mM} \mathrm{KPi} \mathrm{pH} 8.0$ buffer. Difference spectra were generated by subtraction of the spectrum for ligand-free protein from spectra recorded after each addition of NPG. $K_{D}$ values were determined by plotting the maximal absorbance changes calculated from each difference spectrum as a function of substrate concentration and by fitting the data using Sigma Plot 12.0.

Steady-state kinetics of NADPH consumption for P450 BM3 WT and A2 mutant were measured by a Agilent 8453 UV-vis spectrophotometer by monitoring the NADPH oxidation at $340 \mathrm{~nm}$ and using an extinction coefficient at $340 \mathrm{~nm}$ of $6,220 \mathrm{M}^{-1} \mathrm{~cm}^{-1}$. Reactions were performed in $100 \mathrm{mM} \mathrm{KPi} \mathrm{pH} 8.0$ buffer at $25{ }^{\circ} \mathrm{C}$ using a protein concentration of $0.5 \mu \mathrm{M}, 150 \mu \mathrm{M} \mathrm{NADPH}$ and, when present, saturating amounts of the substrate. Each reaction was initiated by the addition of NADPH to the protein and performed in triplicate. The rate of NADPH consumption was calculated in the first linear part of the reaction.

Stopped-flow experiments - Stopped-flow kinetic experiment were performed on cytochrome P450 BM3 WT and A2 mutant in the absence and in the presence of the substrate NPG in order to determine the rate constant for the formation of the $\mathrm{Fe}^{\prime \prime}(\mathrm{CO})$ complex which is strictly dependent on the rate of electron transfer from NADPH to heme through the reductase domain (BMR). Experiments were performed at $25^{\circ} \mathrm{C}$ in $100 \mathrm{mM} \mathrm{KPi} \mathrm{pH} 8.0$ buffer using an Hi-Tech Scientific SF-61 stopped-flow system in a sealed glove box with $\mathrm{O}_{2}$ concentration $<10 \mathrm{ppm}$. Prior to analysis, all buffers and the solution used were saturated with carbon monoxide $(\mathrm{CO})$ by bubbling with the gas for at least 5 minutes. The enzyme $(10 \mu \mathrm{M})$ present in the first syringe was mixed with NADPH $(200 \mu \mathrm{M})$ in a second syringe in a 1:1 ratio. For the substrate bound form, P450 BM3 WT and A2 mutant were saturated with the ligand NPG (15 $\mu \mathrm{M})$ prior to be analysed. Absorption changes at $450 \mathrm{~nm}$ (reflecting formation of the $\mathrm{Fe}^{\prime \prime}(\mathrm{CO})$ adduct) were monitored for $5 \mathrm{~s}$ after stopped-flow mixing. Each reaction was performed at least in quadruplicate. Data were fitted using Kinetic Studio data analysis software.

Redox potentiometry - Spectroelectrochemical experiment were carried out at $25^{\circ} \mathrm{C}$ in a quartz cuvette placed in a cuvette holder adaptor connected by a fiber optic cable to a spectrophotometer that recorded the spectra and simultaneously to a potentiostat to measure the redox potential. The measurements were performed in 
anaerobiosis $\left(\mathrm{O}_{2}\right.$ concentration was less than $\left.10 \mathrm{ppm}\right)$ by a continuous flow of nitrogen gas within the otherwise sealed glove box using an $\mathrm{Ag} / \mathrm{AgCl}$ reference electrode and a laminar gold working electrode. Sodium dithionite was used as the reducing agent for the titrations, aliquots of $1.25 \mu \mathrm{M}$ were added each time to the protein solution until complete reduction was observed. Protein and sodium dithionite solutions were prepared in $100 \mathrm{mM} \mathrm{KPi} \mathrm{pH} 8.0$ buffer. After each addition of sodium dithionite the sample was stirred and the system was allowed to equilibrate for at least 15 minutes. After equilibration at each potential the optical spectrum was recorded. Redox mediators (methylene blue, O-safranine, phenazine methosulfate, anthraquinone-2,6-disulfonic acid, benzyl viologen and methyl viologen) were also added to the sample to facilitate electrochemical communication between the protein and the electrode. The concentration of the mediators was 30 times less compared to that of the protein, $3 \mu \mathrm{M}$ protein versus $0.1 \mu \mathrm{M}$ mediator. All the redox mediators (except benzyl viologen and methyl viologen that were diluted in water) were prepared in methanol to a final concentration of $5 \mathrm{mM}$. Then a $0.05 \mathrm{mM}$ solution of each mediator was prepared using $100 \mathrm{mM} \mathrm{KPi} \mathrm{pH} \mathrm{8.0.} \mathrm{Finally,} \mathrm{putting} \mathrm{all} \mathrm{the}$ mediators together we prepared the mix used in the experiment. Reduction potentials, expressed relative to the standard hydrogen reference electrode (NHE), were obtained from the experimental data points fitted to the theoretical Nernst equation by fitting the percentage of oxidized fraction of the protein calculated using the absorbance values at $419 \mathrm{~nm}$ for the ligand-free and $398 \mathrm{~nm}$ for the substratebound protein versus the potential. Each plot is the result of at least three experiments.

Differential scanning calorimetry (DSC) - DSC was carried out on a Microcal VPDSC instrument. Data analysis was performed using Microcal Origin software. The parameters used were as follows: $25-105{ }^{\circ} \mathrm{C}$ temperature gradient, $90{ }^{\circ} \mathrm{C} / \mathrm{h}$ scan rate, 10 minutes prescan thermostat. Background scans were carried out with degassed $100 \mathrm{mM} \mathrm{KPi} \mathrm{pH} 8.0$ buffer and saturated with NPG for the substrate-bound samples. All samples were run using $10 \mu \mathrm{M}$ proteins and saturating amounts of the substrate, when present.

\section{Results and discussion}

\section{Crystal structures of the heme domain of A2}


The crystal structure of the heme domain of P450 BM3 A2 in the substrate-free and bound forms was solved at 2.4 and $1.97 \AA$ resolution, respectively. Data collection and refinement statistics are reported in Table 1.

Figure $1 \mathrm{~A}$ shows a superimposition of the crystal structure of P450 BMP A2 and the substrate-free structure of the wild type protein (PDB ID 1 BU7) [21]. The overall RMSD is $0.625-0.721 \AA$, depending on the monomer taken into account and superimposed, and the most significant changes are seen in F- and G- helices, that are part of the substrate access channel in P450 BM3 [21]. In line with previously published crystal structures of different cytochromes P450, the F-G loop and part of the G-helix are unresolved in A2 mutant or present the highest B factors, suggesting a high degree of disorder that has been attributed to a high level of flexibility of this part of the P450 fold [34-36]. The high degree of flexibility in A2 mutant is the result of the replacement of Asp251 with a glycine, that significantly affects the structure since the salt bridge involving Asp251 and Lys224 is broken, resulting in repositioning of helix $G$ (Figure 2A). However, the movement of helix $G$ is restricted by the new conformation adopted by Arg255 side-chain that allows the conservation of a salt bridge with Asp217 found also in the WT protein (Figure 2A). This side chain elongation of Arg255 was also found in another mutant of P450 BM3, named KT2, carrying 5 mutations and with enhanced activity compared to the WT protein $[37,38]$. The second mutation of $A 2, \mathrm{Gln} 307 \mathrm{His}$, is located on the protein surface and involves the last residue of helix J'. This mutation removes the hydrogen bond present between GIn307 and Asp300 and introduces a new hydrogen bond between GIn307 and Ser304 (Figure 2B). As a result, the local structure is not significantly altered by this mutation compared to the wild type protein.

When the BMP A2 mutant structure is superimposed to that of substrate-bound BMP wild type, the RMSD decreases to 0.559-0.619 and only minor differences in helix $G$ and some external loops are present (Figure 1B). Thus, the mutations introduced in A2 mutant cause a conformational change similar to that induced by substrate binding in the wild type protein. Interestingly, this mutation-induced conformational change was also found for other mutants of cytochrome P450 BM3 but it is was mainly due to active site mutations, or by a combination of five mutations $[10,38]$. Here, the same conformational effect is achieved by only one mutation breaking a key salt bridge on the protein surface. This conformational change is significant since it has a long-range effect on the structure of the active site of the protein. In fact, a 
close look in the catalytic pocket shows some subtle changes that are usually triggered by substrate binding. First, the water molecule present as sixth ligand of the heme iron atom is in an off-axial position by $12^{\circ} \mathrm{C}$ compared to BMP WT structure and at a distance of $2.8 \AA$ (Figure $3 \mathrm{~A}$ ). This is consistent with the unstable predominantly low spin state observed in the variant that is however very sensitive to slight changes of ionic strength and $\mathrm{pH}$. Secondly, the residue Phe87, a residue involved in a rotational movement when the substrate is bound, is already almost completely rotated in the substrate-free form of A2 mutant, as in the substrate-bound WT structure (Figure 3A). Since it has been proposed that the spin equilibrium in P450 BM3 is affected by Phe87, this is an important change since it facilitates both the access of substrates to the active site of the protein and the water displacement $[39,40]$. Moreover, some residue side chains such as Phe261 and His266 that undergo major changes upon substrate binding, are already in the substrate-bound conformation. Finally, the so-called kink region of helix I is also more similar to the substrate-bound WT. In fact, the water molecule present in the groove formed by the disruption of the intrahelical hydrogen bond pattern in the substrate-free WT enzyme is missing in A2 mutant (Wat2 in Figure 3A). As a result, the kink is less pronounced compared to the substrate-bound WT enzyme and this is due to the disruption of the hydrogen bonds between Leu262CO-His266NH and Ala264CO-Thr268NH (Figure 3B). Moreover a water molecule, corresponding to Wat501 in the structure of BMP WT in complex with N-palmitoylglycine (1JPZ), is present in a similar position and forms hydrogen bonds with Ala264, Thr268 and Thr269 (Wat3 in Figure 3A). Ala264 also forms a hydrogen bond with the axial water ligated to the heme iron as in the WT enzyme (Figure 3B).

The crystal structure of A2 mutant in complex with N-palmytoilglycine (NPG), a known substrate of P450 BM3 [22], was also solved and the electron density of the substrate was visible in one of the monomer (Figure 4A). The overall structure is very similar to that of substrate-free A2 mutant (RMSD $0.583 \AA$ ). The substrate NPG resulted in a slightly different position in A2 mutant compared to the WT enzyme [22] and bound to Tyr51, GIn73 and Ala74 through hydrogen bonds (Figure 4A). In our structure, Arg47 is not involved in NPG binding whereas a previously published crystal structure BMP WT in complex with NPG shows that this residue is involved in binding [42]. 
The axial water ligand is now $3 \AA$ far away from the heme iron in an off-axial location increased by $14^{\circ}$ and the water molecule in the helix I groove overlays with Wat501 in BMP WT-NPG complex structure (PDB 1JPZ) and with the water molecule found in substrate-free $A 2$ mutant (Figure 4B). Thus, upon substrate binding, even if with differences compared to the WT enzyme, there is a relocation of the water molecules responsible for the spin shift and thought to be important for oxygen binding and catalysis [22].

Since the mutant $A 2$ has been shown to have new catalytic abilities toward diclofenac, ibuprofen and tolbutamide [9], co-crystallization experiments were also performed by complexing the enzyme with the three drugs at saturating concentrations before crystallization and monitoring the spin shift associated to the drug binding. For the A2-diclofenac complex, diffraction data were collected at $2.0 \AA$ resolution and the structure solved. A positive density in the active site and in proximity of Arg47 in the difference electron density map was observed but fitting a diclofenac molecule resulted in an increase in the $\mathrm{R}_{\text {free }}$ factor during refinement even if alternative conformations of the drug were used to fit the electron density. This result suggests that the drug enters the active site of the protein but it is highly mobile, most probably due to the lack of stable interactions with the residues of the substrate binding site. Indeed, these residues are not changed in A2 mutant compared to the wild type protein that is not able to bind and turn over the drug and, in fact, the $K_{D}$ values measured for the substrate NPG is similar for WT and A2 mutant $(0.73 \pm 0.07$ and $0.54 \pm 0.07 \mu \mathrm{M}$, respectively).

The structural data, taken together, suggest that the mutation Asp251Gly introduces a higher degree of flexibility of part of the access channel compared to WT, that can increase the probability to introduce new molecules to the active site of the protein. The mutation is responsible for an overall open-to-close conformational transition with a long-range effect on the active site, where the rotation of Phe87 facilitates the entrance of substrates close to the heme iron. Moreover, a rearrangement of the active site water molecules, similar to the one induced by substrate binding in the WT protein, is seen in A2 mutant.

\section{Differential scanning calorimetry (DSC).}


In order to investigate the role of the conformational change of the protein in relation to its stability and flexibility, differential scanning calorimetry experiments were performed fro BMP WT and A2 in the absence and presence of the NPG substrate. The results are shown in Figure 5 and the melting temperatures $\left(T_{m}\right)$ calculated are reported in Table 2.

The DSC profile of the WT protein in the absence of substrate shows a wide peak that can be deconvoluted into two components with $T_{m 1}$ of 55.8 and $T_{m 2}$ of $61.4^{\circ} \mathrm{C}$. Upon NPG binding, the two transitions become better resolved with a $T_{m 1}$ of 61.4 and a $T_{m 2}$ of $66.5^{\circ} \mathrm{C}$. The presence of two transitions could be ascribed to the presence in BMP of two sub-domains [43] while the increase of the $T_{m}$ values observed upon substrate addition is consistent with the additional interactions between the protein and the substrate leading to a conformational change known to decrease the flexibility of the protein $[21,22]$.

Based on the knowledge of the BMP A2 structure described in the previous section, it might be expected that the DSC profile of A2 mutant is similar to that of the substrate-bound WT. Figure $5 \mathrm{C}$ indeed shows that the substrate-free A2 mutant displays two transitions even better resolved than those of the substrate-bound WT. However, the $T_{m 1}$ and $T_{m 2}$ values are found to be 53.6 and $61.7^{\circ} \mathrm{C}$ respectively, that are lower than the corresponding values found for substrate-bound WT. This can be ascribed to the absence of the stabilizing interactions of A2 mutant with the substrate. Moreover, the comparison of $T_{m 1}$ and $T_{m 2}$ values of the substrate-free proteins, show a lower $\mathrm{T}_{\mathrm{m} 1}$ value for the substrate-free $\mathrm{A} 2$ mutant. In line with the structure of BMP A2, this suggests a higher degree of flexibility in this protein as indicated by the presence of disordered regions. The effect of substrate addition to A2 mutant on the DSC profile is shown in Figure 5D. The apparent less resolved peak profile is due to the presence of a new component $\left(T_{m 3}\right)$ at $66.0^{\circ} \mathrm{C}$, while $T_{m 1}$ and $T_{m 2}$ remain comparable to that found in the substrate-free $A 2$. This is consistent with a more rigid protein conformation imposed by the presence of the substrate as also observed for WT. However, in substrate-bound A2, the presence of a flexible component represented by $T_{\mathrm{m} 1}$ still persists.

Our data are also in line with the results from the crystal structures of other mutants of cytochrome P40 BM3 with catalytic new abilities compared to WT $[10,38]$ where the effect of the mutations is to promote the conformational change and the structural rearrangements that bring the protein to adopt a conformation similar to the 
substrate-bound form of the WT protein. However, for those variants the conformational rearrangements are induced either by single and double active site mutations or by a combination of mutations far from the active site [10,38]. For some of them, the catalytic improvements of the variants were explained in terms of a decrease in the free energy barrier necessary to the protein for the transition from the substrate-free to the -bound conformations [10,38]. In fact, DSC experiments showed that the addition of substrate induces only a small thermal stabilization in the mutants (already in the closed conformation) compared to the WT protein, where a stabilization by $5-6^{\circ} \mathrm{C}$ is achieved by substrate addition upon the change from the open to the closed conformation [10]. Our data data suggest that the removal of a salt bridge in A2 mutant has an effect on the stability of the protein and, from the crystallographic data, this can be explained with the increase in the conformational flexibility of the G-helix found in the mutant $A 2$.

\section{Impact of structure on P450 BMP A2 functional properties}

The structure of the A2 mutant shows a rearrangement of the water molecules within the active site cavity (Figure 3 ). As this could affect the redox properties of the metal center, spectroelectrochemistry was used to determine the reduction potential of the mutant. The results are summarized in Table 3. Though both WT and A2 show a shift of the reduction potential $\left(E_{m}\right)$ toward positive values upon substrate binding, the $E_{m}$ value of substrate-free $A 2$ is within the error the same as that of the substrate bound WT. This can be explained by the analysis of the x-ray structure of substrate-free A2 where the position of the water molecule is close to that found in the substrate-bound WT. Addition of the substrate leads to a $42 \mathrm{mV}$ shift toward positive values for the $\mathrm{WT}$, while in the A2 mutant this leads to only a $+26 \mathrm{mV}$ shift. The lower positive shift in reduction potential observed for the mutant $A 2$ is also coherent with the different position of the water molecules.

All together these results can be explained by the partially off-axial position of the water molecule found in $\mathrm{A} 2$, as well as the pattern of hydrogen bond involving the residues of the helix I and the water molecules (Figure 3B) and, more in general, the changed structural environment compared to the WT protein. Moreover, the reduction potential of the mutant $A 2$ moves toward even more positive values when the substrate NPG is added, consistent with the movement of the water molecule to a more distant and off-axial position (Figure 4B). 
Since the substrate-induced shift of the reduction potential toward positive values triggers the first electron transfer in the catalytic cycle of cytochrome P450, stopped flow measurements were used to follow the first electron transfer kinetics from NADPH to the heme domain of P450 BM3 WT and A2. This is possible because the reduced form of the heme iron atom is able to bind $\mathrm{CO}$ and form a complex with a typical absorption band at $450 \mathrm{~nm}$.

Figure 7 shows the results obtained from the two proteins in the absence and presence of the substrate NPG. The increase at $450 \mathrm{~nm}$ was better fitted to a biexponential as a function of time that led to the rate constants $\left(k_{1}\right.$ and $\left.k_{2}\right)$ reported in Table 3. This behavior was previously observed for BMP WT and other mutants and can be attributed to the presence of a spin equilibrium leading to two populations of protein in high and low spin, respectively (38). The first rate for the mutant A2 is 2folds higher compared to the WT enzyme. When the substrate NPG is added, as expected, the electron transfer rate increases by 2-folds for the WT protein and this is consistent with the shift of the reduction potential toward positive values previously observed. For A2, the value remains unchanged upon substrate addition as the reduction potential is similar for the substrate-free and -bound proteins, suggesting that the substrate-free conformation of the enzyme is already "prone" to accept the electrons.

The results suggest that the conformational change observed in BMP A2 induce a shift of the reduction potential toward positive values favoring the first electron transfer. This means that, when a substrate is accepted in the active site, the mutant is more "ready" than the WT protein to go though the catalytic cycle. This is confirmed by the results shown in Table 3, where the NADPH basal consumption of P450 BM3 WT and A2 in the presence of oxygen measured at $340 \mathrm{~nm}$ is reported. As it can be seen, the rates of NADPH consumption is 4-folds higher in P450 BM3 A2 compared to the WT protein, suggesting that electrons are flowing through the system to oxygen faster than in WT, even if a substrate is not present. This last feature is usually associated to the uncoupling of reducing equivalents for reactive oxygen species production rather than for product formation found in cytochromes $\mathrm{P} 450[1,44]$. This may be the reason why the turnover rate for drugs in A2 mutant is much lower than the NADPH consumption rate, suggesting a high level of uncoupling [9]. Furthermore, these data confirm that a slower electron transfer is usually associated to a higher level of coupling [45-47]. 


\section{Conclusions}

In conclusion, the crystal structure of P450 BMP A2 together with the functional data highlights the importance for catalysis of mutations far from the active site but having long-range effects on it. From a structural point of view, the ability to recognize new substrates can be achieved by a specific mutation in a plastic region of substrate access channel that becomes more flexible and facilitates the transition from the open to the closed conformation of the enzyme as well as substrate entrance. The conformational change is responsible for a series of events in the active site that trigger the shift of the reduction potential toward positive values that facilitates the electron flow through the system compared to the WT protein.

The benefit of the mutations can be seen in terms of a higher degree of flexibility of the mutant compared to WT that facilitates the access of substrates also due to the reorientation of specific side chains such as Phe87. Once the substrates are accepted, the protein is in a catalytically ready conformation, where the structural rearrangements are key to trigger the first events of the P450 catalytic cycle. Thus, the typical cascade of events usually associated with substrate binding (i.e. conformational change, water displacement, shift of the reduction potential and first electron transfer) that represents a fine control mechanism in P450 BM3 WT is at least partially lost in mutant A2 that behaves similar to a "loaded gun" catalyst. Indeed, as expected from a first round of random mutagenesis, the mutations produced the so-called "generalist" [48] that can be used for other rounds of directed evolution to generate variants more specific toward the substrates of interest.

\section{Acknowledgements}

This work was supported by the grant FIRB (project RBFR12FI27_004, awarded to G.

Di Nardo) and Progetto Ateneo-San Paolo 2012 (project SADJATEN12, awarded to S. Sadeghi). 


\section{References}

[1] Ortiz de Montellano, P.R. (2015) Plenum Publisher. New York, NY: Springer.

[2] Guengerich, F.P. (2009) Chem. Res. Toxicol. 22(2): 237-238.

[3] Di Nardo, G.; Fantuzzi, A.; Sideri, A.; Panicco, P.; Sassone, C.; Giunta, C.; Gilardi, G. (2007) J. Biol. Inorg. Chem. 12(3): 313-323.

[4] van Vugt-Lussenburg, B.M.; Stjernschantz, E.; Lastdrager, J.; Oostenbrink, C.; Vermeulen, N.P.; Commandeur, J.N. (2007) J. Med. Chem. 50(3): 455-461.

[5] Damsten, M.C.; van Vugt-Lussenburg, B.M.; Zeldenthuis, T.; de Vlieger, J.S.; Commandeur, J.N.; Vermeulen, N.P. (2008) Chem. Biol. Interact. 171(1): 96-107.

[6] Sawayama, A.M.; Chen, M.M.; Kulanthaivel, P.; Kuo, M.S.; Hemmerle, H.; Arnold, F.H. (2009) Chem. Eur. J. 15(43): 11723-11729.

[7] Reinen, J.; van Leeuwen, J.S.; Li, Y.; Sun, L.; Grootenhuis, P.D.; Decker, C.J.; Saunders, J.; Vermeulen, N.P.; Commandeur, J.N. (2011) Drug Metab. Disposit. 39: 1568-1576.

[8] Rentmeister, A.; Brown, T.R.; Snow, C.D.; Carbone, M.N.; Arnold, F.H. (2011) ChemCatChem. 3(6): 1065-1071.

[9] Tsotsou, G.E.; Sideri, A.; Goyal, A.; Di Nardo, G.; Gilardi, G. (2012) Chemistry. 18(12): 3582-3588.

[10] Butler, C.F.; Peet, C.; Mason, A.E.; Voice, M.W.; Leys, D.; Munro, A.W. (2013) J. Biol. Chem. 288(35): 25387-25399.

[11] Venkataraman, H.; Verkade-Vreeker, M.C.; Capoferri, L.; Geerke, D.P.; Vermeulen, N.P.; Commandeur, J.N. (2014) Bioorg. Med. Chem. 22(20): 5613-5620.

[12] Kim, D.H.; Kim, K.H.; Kim, D.H.; Liu, K.H.; Jung, H.C.; Pan, J.G.; Yun, C.H. (2008) Drug Metabolism and Disposition. 36(11): 2166-2170.

[13] Kim, D.H.; Ahn, T.; Jung, H.C.; Pan, J.G.; Yun, C.H. (2008) Drug Metabolism and Disposition. 37(5): 932-936.

[14] Di Nardo, G.; Gilardi, G. (2012) Int. J. Mol. Sci. 13(12): 15901-15924.

[15] Narhi, L.O.; Fulco, A.J. (1986) J. Biol. Chem. 261(16): 7160-7169.

[16] Boddupalli, S.S.; Oster, T.; Estabrook, R.W.; Peterson, J.A. (1992) J. Biol. Chem. 267(15): 10375-10380.

[17] Urlacher, V.B.; Girhard, M. (2012) Trends Biotechnol. 30(1): 26-36.

[18] Bernhardt, R. (2006) J. Biotechnol. 124(1): 128-145.

[19] Whitehouse, C.J.; Bell, S.G. Wong, L.L. (2012) Chem. Soc. Rev. 41(3): 12181260. 
[20] Jung, S.T.; Lauchli, R.; Arnold, F.H. (2011) Curr. Opin. Biotechnol. 22(6): 809817.

[21] Sevrioukova, I.F.; Li, H.; Zhang, H.; Peterson, J.A.; Poulos, T.L. (1999) Proc. Natl. Acad. Sci. USA. 96(5): 1863-1868.

[22] Haines, D.C.; Tomchick, D.R.; Machius, M.; Peterson, J.A. (2011) Biochemistry. 40(45): 13456-13465.

[23] Valetti, F.; Sadeghi, S.J.; Meharenna, Y.T.; Leliveld, S.R.; Gilardi, G. (1998) Biosens. Bioelectron. 13(6): 675-685.

[24] Omura T.; Sato, R. (1964) J. Biol. Chem. 239(): 2370-2378.

[25] De Sanctis, D.; Beteva, A.; Caserotto, H.; Dobias, F.; Gabadinho, J.; Giraud, T.; Gobbo, A.; Guijarro, M.; Lentini, M.; Lavault, B.; Mairs, T.; McSweeney, S.; Petitdemange, S.; Rey-Bakaikoa, V.; Surr, J.; Theveneau, P.; Leonard, G.A.; MuellerDieckmann, C. (2012) J. Synchrotron Radiat. 19(3): 455-461.

[26] Juanhuix, J.; Gil-Ortiz, F.; Cuní, G.; Colldelram, C.; Nicolás, J.; Lidón, J.; Boter, E.; Ruget, C.; Ferrer, S.; Benach, J. (2014) J. Synchrotron Radiat. 21(4): 679-689.

[27] Kabsch, W. (2010) Acta Crystallogr. D Biol. Crystallogr. 66(2): 125-132.

[28] Evans, P.R.; Murshudov, G.N. (2013) Acta Crystallogr. D Biol. Crystallogr. 69(7): 1204-1214.

[29] Vagin, A.; Teplyakov, A. (1997) J. Appl. Cryst. 30: 1022-1025.

[30] Winn, M.D.; Ballard, C.C.; Cowtan, K.D.; Dodson, E.J.; Emsley, P.; Evans, P.R.; Keegan, R.M.; Krissinel, E.B.; Leslie, A.G.W.; McCoy, A.; McNicholas, S.J.; Murshudov, G.N.; Pannu, N.S.; Potterton, E.A.; Powell, H.R.; Read, R.J.; Vagin, A.; Wilson, K.S. (2011) Acta Crystallogr. D Biol. Crystallogr. 67: 235-242.

[31] Emsley, P.; Cowtan, K. (2004) Acta Crystallogr. D Biol. Crystallogr. 60: 21262132.

[32] Murshudov, G.N.; Vagin, A.A.; Dodson, E. J. (1997) Acta Crystallogr. D Biol. Crystallogr. 53(3): 240-255.

[33] Adams, P.D.; Afonine, P.V.; Bunkoczi, G.; Chen, V.B.; Davis, I.W.; Echols, N.; Headd, J.J.; Hung, L.W.; Kapral, G.J.; Grosse-Kunstleve, R.W.; McCoy, A.J.; Moriarty, N.W.; Oeffner, R.; Read, R.J.; Richardson, D.C.; Richardson, J.S.; Terwilliger, T.C.; Zwart, P.H. (2010) Acta Crystallogr. D Biol. Crystallogr. 66: 213-221.

[34] Li, H.; Poulos, T.L. (1995) Acta Crystallogr. D Biol. Crystallogr. 51(1): 21-32.

[35] Hasemann, C.A.; Kurumbail, R.G.; Boddupalli, S.S.; Peterson, J.A.; Deisenhofer, J. (1995) Structure 3(1): 41- 62.

[36] Ost, T.W.; Clark, J.; Mowat, C.G.; Miles, C.S.; Walkinshaw, M.D.; Reid, G.A.; Chapman, S.K.; Daff, S. (2003) J. Am. Chem. Soc. 125(49): 15010-15020.

[37] Whitehouse, C.J.; Bell, S.G.; Tufton, H.G.; Kenny, R.J.; Ogilvie, L.C.; Wong, L.L. (2008) Chem. Commun. (Camb.) 28(8): 966-968. 
[38] Whitehouse, C.J.; Yang, W.; Yorke, J.A.; Tufton, H.G.; Ogilvie, L.C.; Bell, S.G.; Zhou, W.; Bartlam, M.; Rao, Z.; Wong, L.L. (2011) Dalton Trans. 40(40): 1038310396.

[39] Joyce, M.G.; Girvan, H.M.; Munro, A.W.; Leys, D. (2004) J. Biol. Chem. 279(22): 23287-23293.

[40] Ravichandran, K.G.; Boddupalli, S.S.; Hasermann, C.A.; Peterson, J.A.; Deisenhofer, J. (1993) Science. 261(5122): 731-736.

[41] Li, H.; Poulos, T.L. (1997) Nat. Struct. Biol. 4(2): 140-146.

[42] Catalano, J.; Sadre-Bazzaz, K.; Amodeo, G.A.; Tong, L.; McDermott, A. (2013) Biochemistry. 52(39): 6807-6815.

[43] Graham, S.E.; Peterson, J.A. (1999) Arch. Biochem. Biophys. 369(1): 24-29.

[44] Degregorio, D.; Sadeghi, S.J.; Di Nardo, G.; Gilardi, G.; Solinas, S.P. (2011) J. Biol. Inorg. Chem. 16(1): 109-116.

[45] Dodhia, V.R.; Fantuzzi, A.; Gilardi, G. (2006) J Biol. Inorg. Chem. 11(7): 903-916.

[46] Di Nardo, G.; Castrignanò, S.; Sadeghi, S.J.; Baravalle, R.; Gilardi, G. (2015) Electrochem. Comm. 52: 25-28.

[47] Sadeghi, S.J.; Gilardi, G. (2013) Biotechnol. Appl. Biochem. 60(1): 102-110.

[48] Tracewell, C.A.; Arnold, F.H. (2009) Curr. Opin. Chem. Biol. 13(1): 3-9. 


\section{Tables}

Table 1. X-ray data collection and refinement statistics for variant A2

\begin{tabular}{|c|c|c|}
\hline & $\begin{array}{c}\text { BMP A2 } \\
\text { PDB ID 5DYP }\end{array}$ & $\begin{array}{c}\text { BMP A2 + NPG } \\
\text { PDB ID 5DYZ }\end{array}$ \\
\hline \multicolumn{3}{|l|}{ Data collection } \\
\hline Space group & $\mathrm{P} 2{ }_{1} 2_{1} 2_{1}$ & $\mathrm{P} 2{ }_{1} 2_{1} 2_{1}$ \\
\hline Cell dimensions $\mathrm{a} / \mathrm{b} / \mathrm{c} / \AA \AA$ & $\begin{array}{c}61.13 \\
118.45 \\
146.95\end{array}$ & $\begin{array}{c}61.21 \\
115.71 \\
143.28\end{array}$ \\
\hline Wavelength $(\AA)$ & 0.98 & 0.98 \\
\hline Resolution $(\AA)$ & 2.40 & 1.97 \\
\hline Average $\mathrm{I} / \sigma(\mathrm{I})$ & $13.2(2.6)^{a}$ & $12.0(2.1)^{a}$ \\
\hline Completeness (\%) & $98.6(99.6)$ & $99.6(94.7)$ \\
\hline Redundancy & $5.5(5.5)$ & $6.5(6)$ \\
\hline $\mathrm{R}_{\text {merge }}$ & $0.07(0.572)$ & $0.09(0.864)$ \\
\hline \multicolumn{3}{|l|}{ Refinement } \\
\hline Average $B$-factor $\left(\AA^{2}\right)$ & 73.0 & 40.0 \\
\hline$R_{\text {work }} / R_{\text {free }}(\%)$ & $22.0 / 25.7$ & $18.6 / 22.4$ \\
\hline r.m.s.d. bond lengths $(\AA)$ & 0.006 & 0.010 \\
\hline r.m.s.d. bond angles $\left({ }^{\circ}\right)$ & 1.228 & 1.309 \\
\hline
\end{tabular}

${ }^{\mathrm{a}}$ Values in parentheses are for the highest-resolution shell. 
Table 2. DSC parameters for BMP WT and BMP A2 in the substrate-free and NPGbound forms.

\begin{tabular}{|c|c|c|c|c|c|c|}
\hline Sample & $\mathbf{T}_{\mathbf{m} 1}$ & $\Delta \mathbf{H}_{1}\left(\mathbf{k c a l ~ m o l}^{-1}\right)$ & $\mathbf{T}_{\mathbf{m} 2}$ & $\Delta \mathbf{H}_{2}\left(\mathbf{k c a l ~ m o l}^{-1}\right)$ & $\mathbf{T}_{\mathbf{m} 3}$ & $\Delta \mathbf{H}_{3}\left(\mathbf{k c l a ~ m o l}^{-1}\right)$ \\
\hline BMP WT & $55.8 \pm 0.3$ & $8.269 \mathrm{E} 4 \pm 5.25 \mathrm{E} 3$ & $61.4 \pm 0.1$ & $7.388 \mathrm{E} 4 \pm 5.09 \mathrm{E} 3$ & & \\
\hline $\begin{array}{c}\text { BMP WT } \\
+ \text { NPG }\end{array}$ & $61.4 \pm 0.1$ & $1.684 \mathrm{E} 5 \pm 4.53 \mathrm{E} 3$ & $66.5 \pm 0.1$ & $1.300 \mathrm{E} 5 \pm 4.32 \mathrm{E} 3$ & & \\
\hline BMP A2 & $53.6 \pm 0.1$ & $1.085 \mathrm{E} 5 \pm 578$ & $61.7 \pm 0.1$ & $6.514 \mathrm{E} 4 \pm 554$ & & \\
\hline $\begin{array}{c}\text { BMP A2 } \\
+ \text { NPG }\end{array}$ & $53.0 \pm 0.2$ & $9.206 \mathrm{E} 4 \pm 4.58 \mathrm{E} 3$ & $60.0 \pm 0.1$ & $1.736 \mathrm{E} 5 \pm 7.38 \mathrm{E} 3$ & $66.0 \pm 0.1$ & $2.803 \mathrm{E} 4 \pm 3.28 \mathrm{E} 3$ \\
\hline
\end{tabular}

Table 3. Reduction potentials, first electron transfer rates in the absence of oxygen and presence of $\mathrm{CO}$ and NADPH consumption rates in the presence of oxygen for P450 BM3 WT and A2.

\begin{tabular}{|c|c|c|c|}
\hline Sample & $\begin{array}{l}\text { Em (vs NHE) / mV } \\
\text { (only heme domain) }\end{array}$ & $\begin{array}{l}\mathrm{Fe}^{\prime \prime}(\mathrm{CO}) \text { complex } \\
\text { formation rates }\left(\mathrm{s}^{-1}\right)\end{array}$ & $\begin{array}{l}\text { NADPH consumption rate (mol } \\
\text { NADPH/mol protein } / \mathrm{min}^{-1} \text { ) }\end{array}$ \\
\hline BM3 WT & $-387 \pm 2$ & $\begin{array}{l}\mathrm{k}_{1}=11.8 \pm 0.8 \\
\mathrm{k}_{2}=1.0 \pm 0.2\end{array}$ & $32.3 \pm 2.0$ \\
\hline BM3 A2 & $-342 \pm 3$ & $\begin{array}{l}\mathrm{k}_{1}=19.8 \pm 0.9 \\
\mathrm{k}_{2}=1.3 \pm 0.1\end{array}$ & $129.0 \pm 1$ \\
\hline BM3 WT + NPG & $-345 \pm 5$ & $\begin{array}{l}\mathrm{k}_{1}=23.4 \pm 1.2 \\
\mathrm{k}_{2}=1.4 \pm 0.1\end{array}$ & $451.6 \pm 3.0$ \\
\hline BM3 A2 + NPG & $-326 \pm 6$ & $\begin{array}{l}\mathrm{k}_{1}=17.6 \pm 1.5 \\
\mathrm{k}_{2}=1.2 \pm 0.1\end{array}$ & $645.2 \pm 3.0$ \\
\hline
\end{tabular}


Figure legends.

Figure 1. Overall crystal structure superimposition of the heme domain (BMP) of P450 BM3 A2 (brown) with A) substrate-free BMP WT (cyan, PDB ID 1BU7) [21] and B) NPG-bound BMP WT (magenta, PDB ID 1JPZ) [22].

Figure 2. Structural overlay of BMP WT and A2 in the regions where the mutation of A2 are located. A) Asp251 is part of the I-helix in BMP WT (cyan) and forms a salt bridge with Lys 224 of G-helix. In A2, the salt bridge cannot be formed because of the Asp251Gly mutation and, as a result, the G-helix moves far away from I-helix. This movement is however restricted by the presence both in WT and A2 of the salt bridge between Asp217 and Arg255 that is in a more extended conformation in A2. B) Local effect of the Gln307His mutation. Gln307 forms a hydrogen bond with Asp300 in the WT (cyan). This hydrogen bond is not more present in A2. A new hydrogen bond is formed between His307 and Ser403 (brown). The local structure is not perturbed by this mutation.

Figure 3. Active site of BMP A2. A) Structural overlays showing the rotation of Phe87 in BMP WT (cyan) as a consequence of substrate binding (magenta). In the active site of BMP A2 (tan), Phe87 is almost completely rotated to the substrate-bound position and this movement probably favors substrate access to the active site. In A2 (brown), the I-helix distortion do to the presence of a water molecule that disrupt the regular intra-helical $\mathrm{H}$-bond pattern (Wat2, cyan), is not present as in the substratebound (magenta) WT protein. A water molecule (Wat3) is instead located where it is in the substrate-bound structure (magenta). B) Hydrogen bond pattern involving the water molecules in A2. The off-axial water molecule is hydrogen bonded to the $\mathrm{CO}$ group of Ala264 that is hydrogen bonded to the water molecule that interrupts the intrahelical hydrogen bond pattern.

Figure 4. Structure of BMP A2 in complex with the substrate NPG. A) Active site of the protein showing an unbiased difference electron density (contoured at $2.5 \mathrm{\sigma}$ ) for the bound N-palmitoylglycine (NPG), and the residues involved in hydrogen bonds with the substrate. B) Structural overlay between substrate-free (brown) and -bound (green) BMP A2, showing the movement of the water molecule Wat1, the rotation of Phe87 and the fixed position of Wat3. 
Figure 5. Differential scanning calorimetry (DSC) profiles for A) BMP WT, B) BMP WT in complex with NPG, C) BMP A2 and D) BMP A2 in complex with NPG.

Figure 6. Spectroelectrochemical titrations of the heme domain of P450 BM3 A2 in A) substrate-free and B) NPG-bound forms. The black traces represent the initial fullyoxidised spectra whereas the red traces represent the fully-reduced final spectra. The insets show the plot of the percentage of oxidized fraction, calculated from the absorbance changes at A) 419 and B) $398 \mathrm{~nm}$ as a function of the potential measured and the fitting to the Nernst equation with the number of electrons fixed at 1.

Figure 7. Stopped flow kinetics of $\mathrm{CO}$ binding for A) BMP WT, B) BMP WT in complex with NPG, C) BMP A2 and D) BMP A2 in complex with NPG. In all cases, the black trace represents the initial spectrum whereas the red trace represents the spectrum after 1 second. The insets represent the plots of the absorbance at $450 \mathrm{~nm}$ as a function of time and fitting to double exponential curves. 

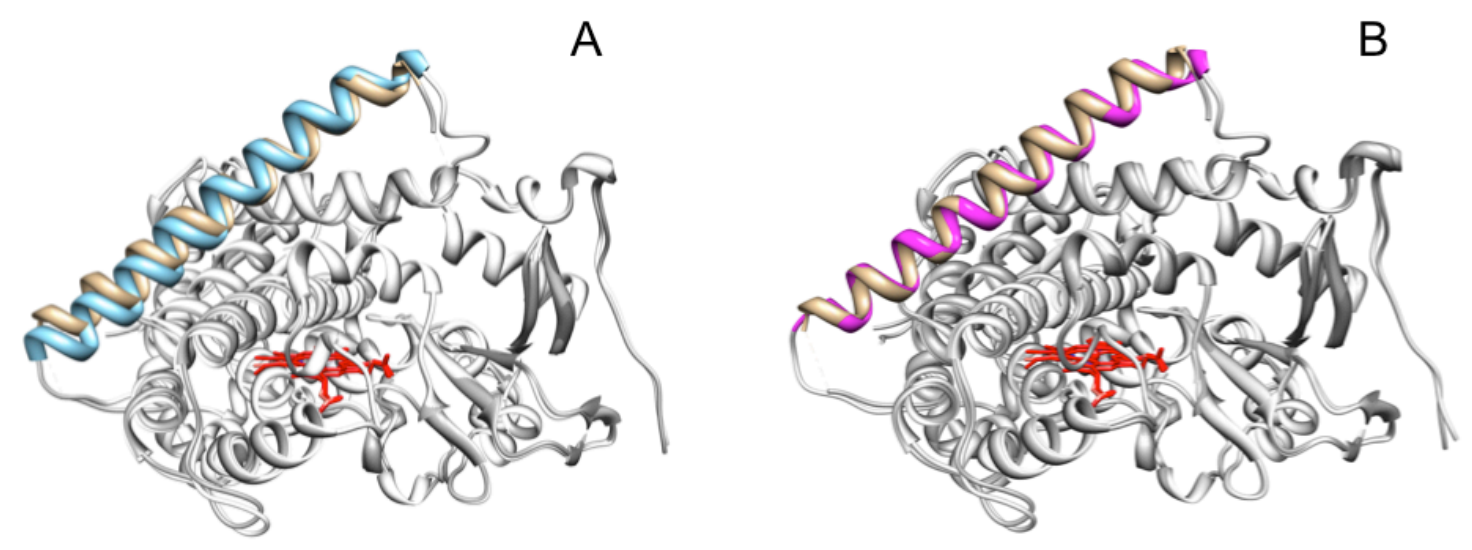

FIGURE 1 

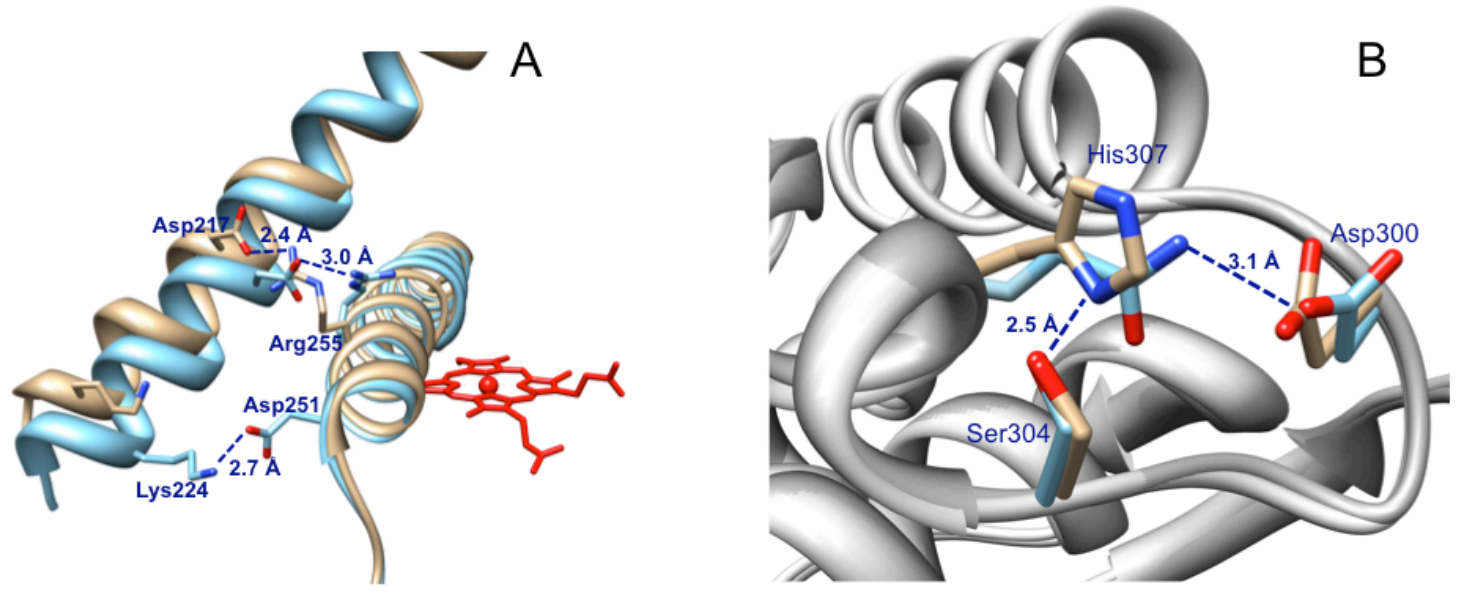

FIGURE 2
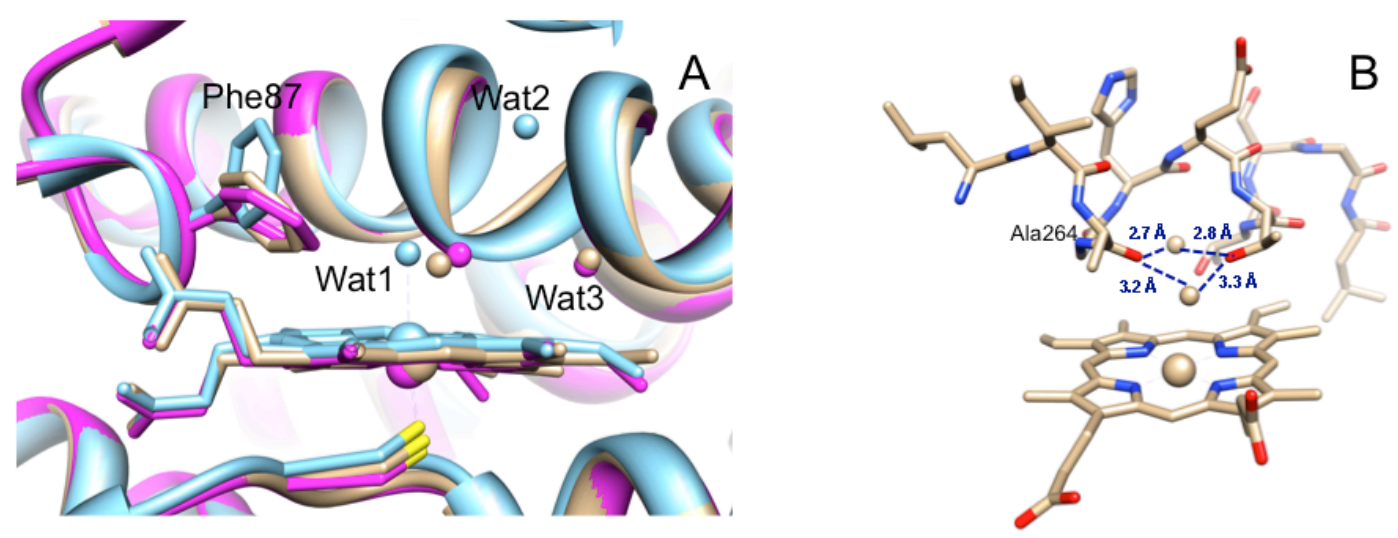

FIGURE 3 

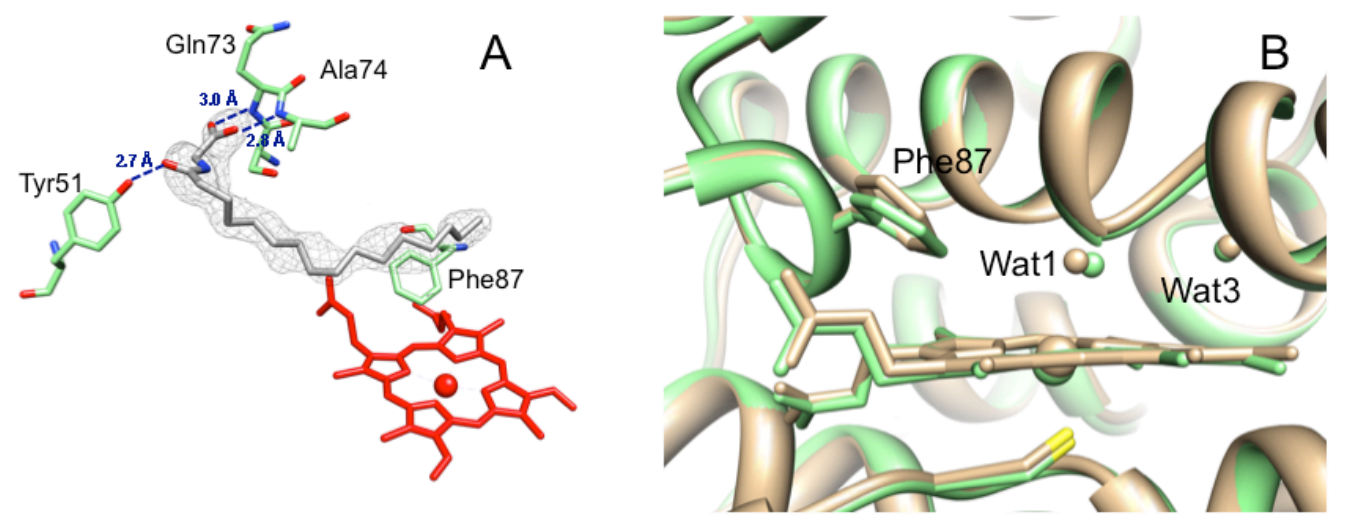

FIGURE 4

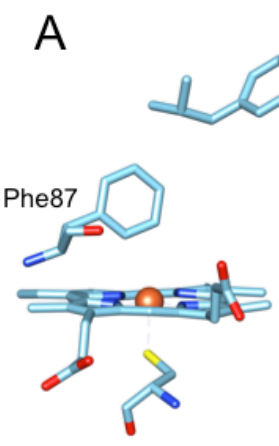

B

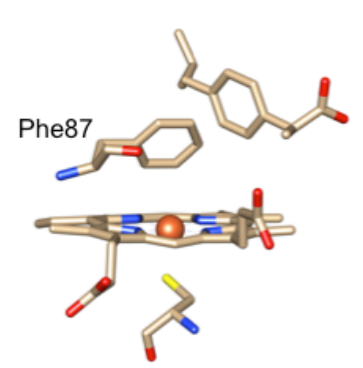

C

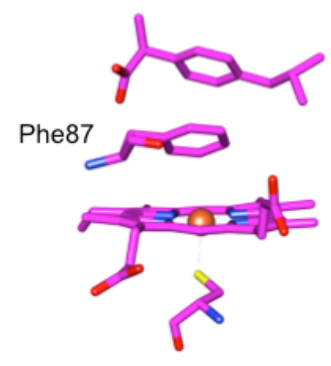

FIGURE 5 

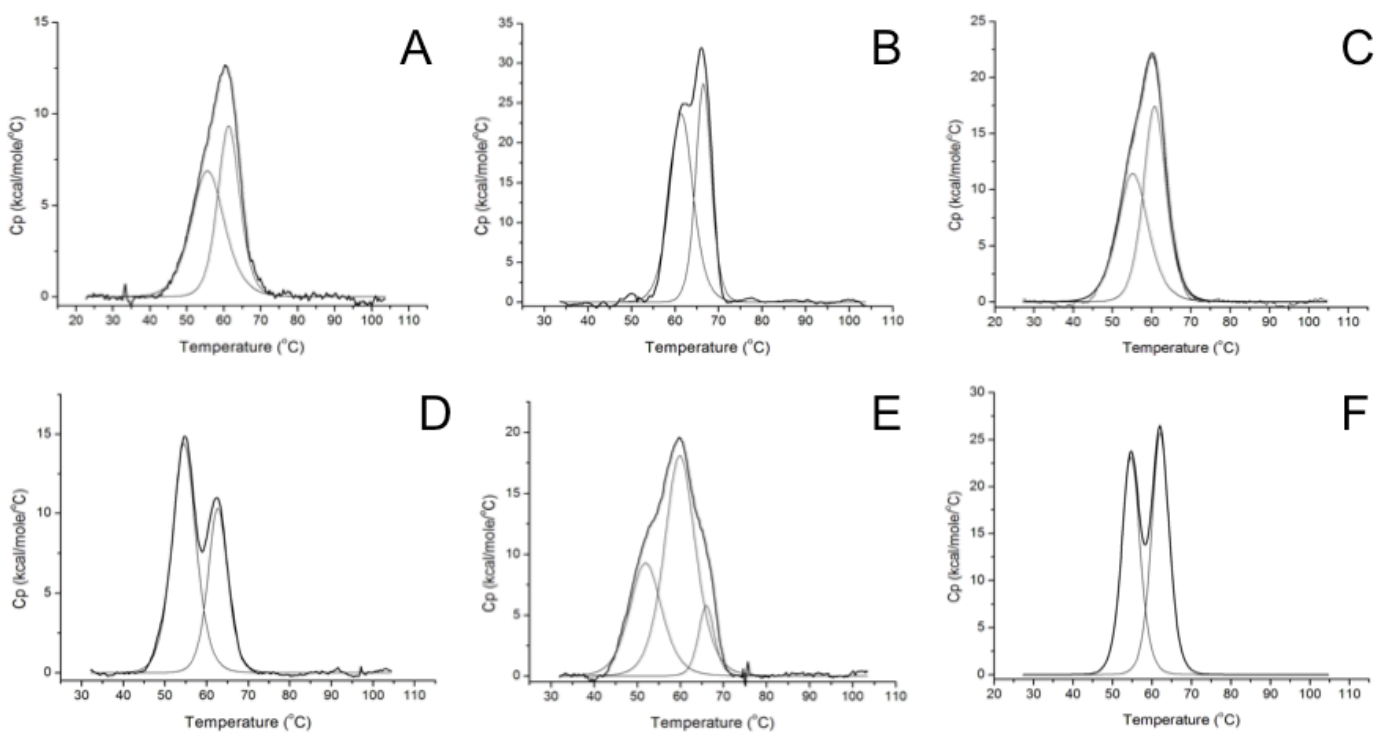

FIGURE 6
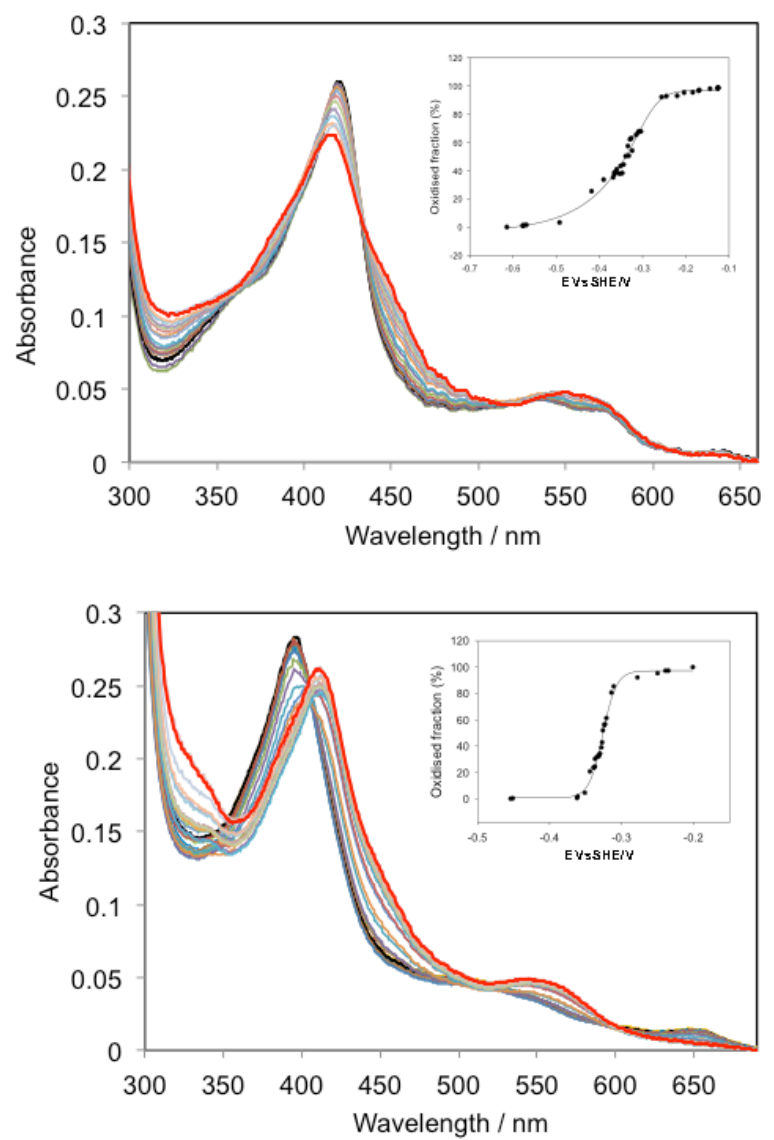

FIGURE 7 

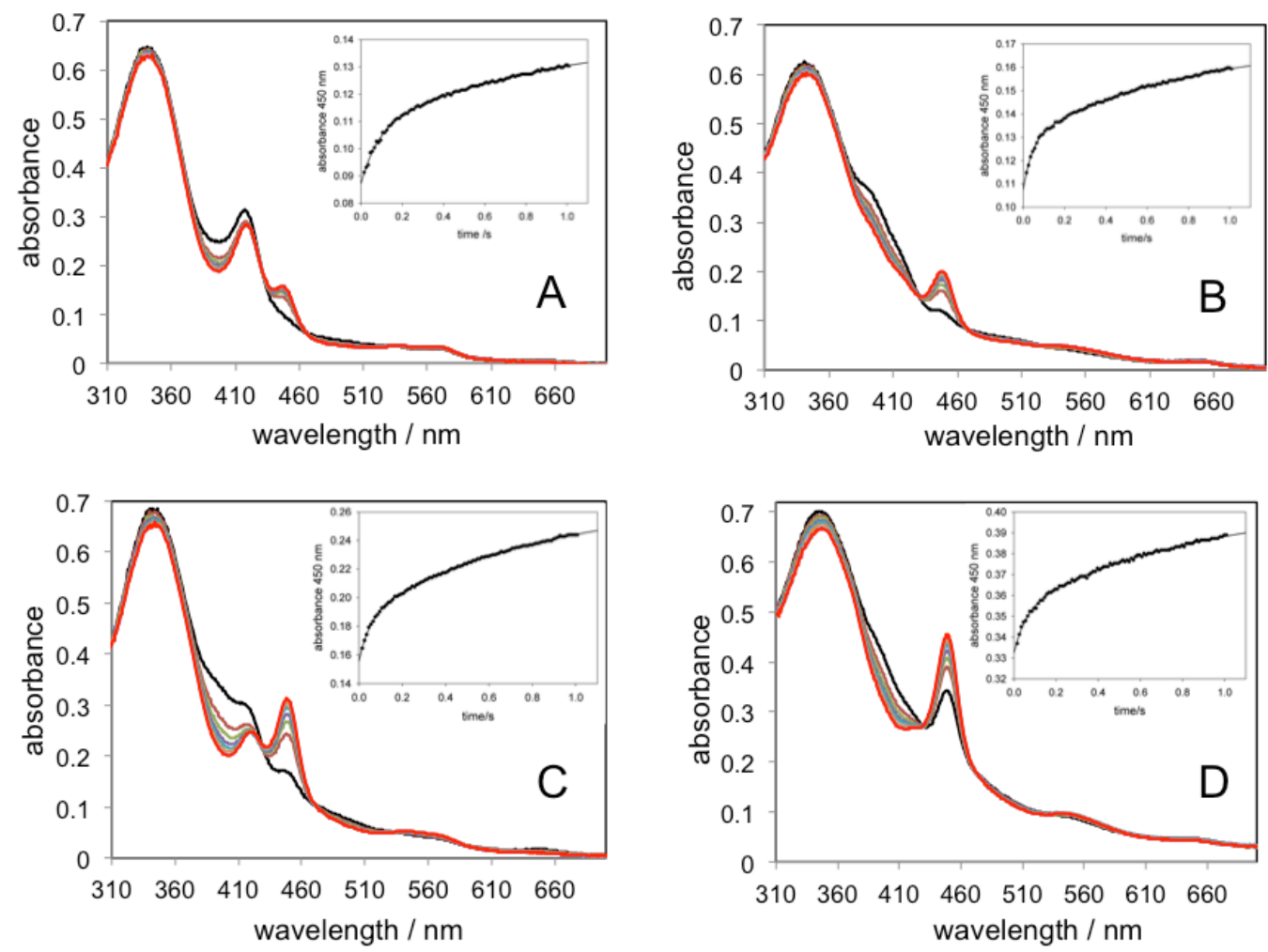

FIGURE 8 